\title{
Mídia, cotidiano e trabalho na escola: fragilização dos vínculos e infantilização dos profissionais docentes
}

Bruno Deusdará" Poliana Arantes ** Luciana Weyne **** $^{*}$

\section{Resumo}

Este artigo discute e analisa discursivamente as discussões acerca do uso de novas tecnologias em sala de aula proposto aos professores por meio de manuais que têm como orientação preparar os profissionais do ensino para atuarem no contexto cada vez mais urgente no universo de práticas midiáticas interativas na educação. Para analisar o material em questão, em especial o material produzido pela prefeitura do Rio de Janeiro em 2011, Escola Entre Mídias, utilizamos o referencial teórico inspirado em uma perspectiva discursiva, de base enunciativa, que remonta à discussão proposta por $\mathrm{M}$. Bakhtin (2004) acerca da perspectiva dialógica da linguagem não dissociada do mundo. Maingueneau (2013), Rocha (2011, 2013, 2014). Como procedimento metodológico, delimitamos do gênero do discurso a que pertence o material em análise. Em seguida, realizamos o levantamento de marcas que remetem aos planos da semântica global (MAINGUENEAU, 2005), com ênfase em intertextualidade e dêixis temporal e espacial. Os resultados da análise apontam para a produção de imagens discursivas de um professor infantilizado.

Palavras-chave: Novas tecnologias. Educação. Discurso.

\footnotetext{
Doutor em Psicologia Social (UERJ). Professor do Programa de Pós-graduação em Letras (Línguística) da Universidade do Estado do Rio de Janeiro.

** Doutora em Estudos da Linguagem (UFMG). Professora do Programa de Pós-graduação em Letras (Línguística) da Universidade do Estado do Rio de Janeiro.

**** Mestranda no Programa de Pós-graduação em Letras (Línguística) da Universidade do Estado do Rio de Janeiro.
}

Data de submissão: mar. 2015 - Data de aceite: maio 2015 http://dx.doi.org/10.5335/rdes.v11i1.5003 


\section{Introdução}

O presente artigo possui um duplo objetivo: de um lado, discute os sentidos atribuídos ao trabalho do professor no cotidiano da formação escolar, a partir da pretensa demanda por uso de novas tecnologias, que vem sendo reafirmada e cristalizada como uma "necessidade" inquestionável. De outro, aborda um debate bastante atual acerca da pertinência teórica do tratamento conferido à dinâmica entre gêneros do discurso e cenografia, tal como foi originalmente formulada por Maingueneau (2013) e seus desdobramentos propostos por Rocha $(2013,2014)$.

No que tange ao tema de nossas análises, temos nos dedicado a refletir sobre os sentidos atribuídos ao trabalho do professor que emergem de uma tensa relação entre os saberes advindos da experiência concreta e as orientações/ os imperativos que são dirigidos a eles sem que, para isso, sejam levadas em consideração as circunstâncias em que o trabalho de formação se exerce. Nesse contexto, o imperativo de uso das chamadas "novas" tecnologias se apresenta como uma demanda que vem sendo construída como um clichê descolado das contingências que a tornariam relevante e que passa a constituir uma grade de avaliação das "novas" práticas escolares em oposição às supostas "velhas" formas. Com efeito, o que se observa é a atribuição como um traço de caráter individual (professores "atualizados" x "obsoletos"), que demandaria da hierarquia apenas iniciativas de estímulo, do que, na verdade, parece corresponder às condições de realização do trabalho.

Dessa forma, de um lado, apresentaremos uma análise do material, a partir do projeto de uma semântica global, segundo a qual não haveria um único plano que viesse condensar os sentidos produzidos por um texto. Nesse sentido, delimitaremos os traços que compõem um perfil de leitor-professor presumido pelo material. De outro, integramos o debate proposto por Rocha $(2013,2014)$, que vem rever o encadeamento entre cena genérica e cenografia, tal como originalmente formulado por Maingueneau (2013). No debate proposto por Rocha, a contribuição se dirige no sentido de ressaltar uma dinâmica de mobilidade constitutiva de qualquer gênero do discurso, mesmo daqueles que se apresentem como pretensamente mais estáveis. No presente artigo, além de confirmar as colocações do autor a esse respeito, situando-se em material que pretende mimetizar a cena hipertextual, ressaltamos o potencial ético de análise de textos sobre o trabalho, implicado no referido deslocamento proposto por Rocha.

Iniciamos nossa discussão, no próximo item, apresentando o material intitulado A escola entre mídias, distribuído aos profissionais de educação da rede municipal do Rio de Janeiro. Nessa descrição, privilegiamos certos aspectos que delineiam uma imagem de leitor professor presumido. 


\section{Descrição do manual: saberes pressupostos e imagens de leitor}

Entre os diversos materiais em que esse tipo de discussão se coloca, elegemos como corpus de análise o manual A escola entre mídias, distribuído aos professores da rede municipal do Rio de Janeiro pela Prefeitura em 2011. Optamos por tratar o referido material como um manual que pretende prescrever orientações aos docentes, considerando sua finalidade proposta, a disposição dos capítulos e as formas de circulação/distribuição nas unidades da rede.

O referido manual pretende divulgar entre os professores informações gerais, que se supõem necessárias ao trabalho pedagógico, além de exemplos de práticas com o uso de tecnologia em escolas da rede. Essa dupla função se observa já na apresentação do material, assinada pela então secretária de Educação Cláudia Costin, em que ele é definido como um livro que apresenta

[...] conceitos fundamentais que orientam as práticas pedagógicas, refletindo sobre a história da civilização escrita, por meio da comunicação entre os homens. Explora os ingredientes para uma pedagogia criativa, o que permite um olhar midiaeducativo sobre o currículo (MULTIRIO, 2011, p. 8).

Cabe ressaltar que a ideia de "pedagogia criativa" pressupõe que outras práticas pedagógicas não o sejam, dando um tom inovador ao material distribuído e, por consequência, desqualificando outras práticas.
Além disso, na introdução, o livro é definido como um material de apoio ao professor e, para tal,

[...] a publicação oferece informações teórico-práticas sobre a aprendizagem mediada por meio da articulação da comunicação com os componentes curriculares, para que se possam criar, desenvolver e avaliar as atividades midiaeducativas, com ênfase na formação de professores e de alunos comunicadores-produtores (MULTIRIO, 2011, p. 10).

Ao se propor a oferecer "informações teórico-práticas", mais uma vez a ideia orientadora do manual pode ser equiparada a uma espécie de receita a ser seguida, como se o material trouxesse uma versão acabada em relação às soluções das demandas dos professores e como se abarcasse todas as necessidades teóricas sobre a tecnologia, sugerindo como o professor deve utilizá-la para garantir condições favoráveis e positivas de sua prática.

Trata-se de uma obra composta por três capítulos. O primeiro deles, intitulado Educação e Comunicação: diálogo pedagógico, é subdividido em três partes: a primeira "A história da civilização escrita por meio da comunicação entre os homens" pretende oferecer informações históricas a respeito de formas de escrita anteriores e posteriores à prensa, rádio, televisão, cinema. Em todas as páginas, há imagens representando o que se diz, a exemplo de pergaminhos, placas de barro da escrita cuneiforme, uma prensa, entre outros. Emprega-se com bastante frequência também o recurso a quadros pretensamente explicativos, intitulados 
"você sabia...", "música" (com trechos de música supostamente contextualizados) e "filme" (com sugestões de filmes relativos às temáticas em tela).

Note-se que algumas imagens ou quadros (sobretudo os de música) não se encontram exatamente contextualizados, como a imagem de uma caravela ou a de Dorival Caymmi na Rádio Nacional, ou ainda um quadro com trechos de músicas que parecem atender apenas a um objetivo lúdico, a exemplo do fragmento sobre "no escurinho do cinema", quando se conta a história do cinematógrafo.

Na sequência, expõe-se uma linha do tempo, indicando a data de surgimento de cada uma das formas de comunicação, ilustradas e associadas a informações que ganham estatuto de curiosidade, pois são tratadas superficialmente e são dadas por meio de descrição geral, por vezes até desnecessária, como, por exemplo, no caso da descrição do surgimento do rádio: "Disseminou a informação transmitida oralmente a distância". Essa seção se conclui com um texto de colaborador, intitulado "A narrativa digital interativa" que problematiza as formas de comunicação e busca dialogar com conceitos do campo teórico, porém com pouco aprofundamento.

No segundo item desse primeiro capítulo, intitulado "Comunicação e diálogo", buscou-se discutir sobre as formas de comunicação a partir de uma concepção e um modelo comunicativos estruturalistas, pois enfatizam que a realização da comunicação aconteceria de forma linear, de modo que a mensagem a ser transmitida seria a realização de um interlocutor, direcionada a um receptor. Percebe-se, nesse sentido, que a discussão feita sobre o processo de comunicação não é atual e não é problematizada, apesar de apontar caminhos tímidos nessa direção.

Esse item do capítulo também procura levar ao professor uma espécie de atualização tecnológica e sugere que a tecnologia pode ser aliada em sala de aula e pode contribuir para a contextualização dos conteúdos em meio digital. No entanto, tais enunciados não estão em relação de aproximação ao texto, eles se encontram separados, destacados e geram um vínculo frágil com esse.

As citações são tão recorrentes nesse item, que consideramos pertinente listar as autorias: Paulo Freire, Pedro Demo, Pierre Babin, Bakhtin, Raquel de Almeida Moraes, Cleide Ramos, Ricardo Petracca, Jesús Martín-Barbero, Marcia Leite, Maria Cecília Martins, Gregório de Matos, Cleide Ramos, Silvana Gontijo, Carlos Fernando de Araújo Jr., Áderson Guimarães Pereira, Marinete D’Angelo, Philippe Perrenoud,

Um quadro intitulado "Uma pausa para refletir" explica o que é "gap geracional" a partir de uma descrição sobre o que os alunos trazem de casa quando chegam à escola. $O$ texto traz constatações corriqueiras, de ordem do senso comum e que ignoram o fato de se colocarem em posição autorizada para refletir sobre práticas cotidianas dos professores. 
No item "revisitando os conceitos de tempo e espaço", são apresentados, novamente, enunciados bastante conhecidos no senso comum: "tem-se a impressão, nos dias atuais, de que o tempo passa mais depressa" (MULTIRIO, 2011, p. 42), mas que não são aprofundados ou discutidos. O item busca, com um pequeno texto e permeado de ilustrações infantilizadas que remetem à figuração do espaço (foguete espacial) e do tempo (ampola do tempo), trazer a discussão sobre como o mundo globalizado por meio das redes de comunicação tem contribuído para a diminuição das fronteiras físicas geográficas.

Em seguida, o item "Midiaeducação: 'ingredientes' para uma pedagogia criativa" pretende, a começar pelo título, apresentar instrumentos para colocar em prática a pedagogia "inovadora" do trabalho com as novas mídias, que é denominado "Midiaeducação". A expectativa levantada pelo título da seção é alimentada ao longo dos textos, que fazem uma apresentação dessa pedagogia autointitulada "inovadora" a partir de quadro justificando a grafia de "midiaeducação", sem hífen.

Já o Capítulo 2, com o título "Um olhar midiaeducativo sobre o currículo", propõe que os Parâmetros Curriculares Nacionais (PCNs) sejam vistos sob a ótica da midiaeducação. Logo na abertura do tópico, há dois grandes boxes explicando o que são os PCNs e o que é o Projeto Político-Pedagógico em uma escola.
Na sequência, há um pequeno artigo sobre o que são competências e habilidades e quais as suas relações com a comunicação e a educação, reiterando o clichê de que as novas tecnologias promovem novas formas de conhecimento.

Já na seção "atravessando fronteiras", ao lado de expressões como "irado", "maneiro" e "curti", o texto sugere que o professor procure ser mais atento ao vocabulário e ao universo dos alunos, para que exista um trabalho comunicativo eficiente. Tal postura mais uma vez sugere a imagem de um professor alienado, que pouco conhece da juventude. Ainda no Capítulo 2, o artigo Necessário e precioso: o diálogo que falta reforça a necessidade de uma mediação de adultos responsáveis para o acesso dos jovens aos meios de comunicação.

Ainda no Capítulo 2, o tópico "Buscando conexões midiaeducativas" se estende por seis páginas de forma prolixa discorrendo sobre o que é um projeto, sobre a importância dos alunos desenvolverem projetos que envolvam as mídias, mas, no final das contas, o projeto prático fica apenas no plano teórico e não encaminha o docente a nenhuma ideia concreta. Já o tópico "quando a tecnologia entra na escola" também repete o clichê de que a tecnologia é uma aliada importante da educação, deixando a desejar no quesito orientações práticas ao docente, além de explicar o que é um hipertexto e como a internet é interativa, como se o professor nunca tivesse tido acesso à internet anteriormente. 
O Capítulo 3, "Som e imagem: um encontro que dá asas à imaginação", que encerra o livro, se propõe a ser mais prático, com exemplos de atividades com o uso de mídias que o professor poderia aproveitar e desenvolver na escola. A abordagem inicial do capítulo mais uma vez destaca a importância do audiovisual para o desenvolvimento dos alunos. A primeira mídia explorada é o rádio. Após uma breve descrição de suas características, como o imediatismo, baixo custo e alcance, o manual propõe que $o$ professor elabore atividades radiofônicas com os alunos. O que parece ser uma boa sugestão de atividade educacional é, na verdade, uma proposta de se produzir um programa de rádio de forma profissional na escola.

O manual sugere que os alunos realizem atividades de encenação, exercendo o papel de locutor, editor, produtor/ redator, repórter, operador de áudio e pauteiro, estrutura típica de grandes veículos de comunicação radiofônica. Há inclusive um box explicando ao professor que o pauteiro é um cargo em extinção no jornalismo, o que demonstra um detalhamento incompatível com as informações óbvias distribuídas ao longo do material.

$\mathrm{Na}$ sequência, são descritos os equipamentos necessários para a produção do material "educativo": duas mesas, um amplificador, duas ou mais caixas de som, mesa de som profissional com alguns canais, fones de ouvido, gravador e microfone, supondo a existência de ambientes de rádio profissionais nas escolas da rede, não encontrados nem mesmo nos grandes veículos de comunicação radiofônica.

Já a segunda proposta se refere à produção de um vídeo pelos alunos. Mais uma vez, o que se propõe é um modelo muito profissional, em que os alunos se dividiriam nas funções de apresentador, produtor, repórter, redator, editor de jornalismo, operador de áudio e luz, ator, roteirista, cinegrafista, diretor, diretor de arte, editor de vídeo e produtor musical. Além de trazer ao professor conceitos técnicos como brainstorming e briefing, o manual também propõe a produção de um roteiro profissional, com conceitos de enquadramento, movimento de câmera e edição de vídeo. Os equipamentos, mais uma vez, são apresentados como simples de serem manuseados e de fácil aquisição: celular ou câmera digital, computador, duas mesas para edição e softwares para edição de vídeo. Para completar o tema, o artigo $T V$ digital interativa: perspectivas para a educação é apresentado na sequência. Apesar de conter em seu título o termo educação, o texto apresenta muitos conceitos técnicos e poucas aplicações na escola.

A terceira e última proposta prática utiliza a internet. A seção começa apresentando o conceito de hiperlink e ensina ao professor a utilizar sites e ferramentas de busca na internet, além de redes sociais. No tópico "responsabilidade em relação à autoria", orienta-se o professor a ensinar ao aluno a pesquisar na internet, sem cópia. Além disso, 
informa ao docente como se proteger nas redes sociais, com estratégias como não revelar dados pessoais, não confiar em tudo que se vê ou lê ou não aceitar ajuda de estranhos ao usar o computador fora de casa. Cria-se, com isso, um perfil de leitor bastante genérico: infantilizado, desconhecedor do ambiente virtual, não iniciado no universo conceitual das novas tecnologias.

Diante disso, A escola entre mídias parece oferecer orientações desequilibradas ao professor e distante de suas práticas discursivas e cotidianas. Se de um lado há um profissionalismo nas propostas práticas oferecidas, de outro, há a apresentação de dicas que pressupõem um despreparo do docente e pouco acesso às informações divulgadas pela grande imprensa.

No próximo item, explicitamos a orientação discursiva a partir da qual nos situamos para realizar nossas análises. Nessa apresentação, privilegiamos o modo como uma proposta de semântica global (MAINGUENEAU, 2005) compreende a instauração de sentidos pelo texto. Diferente do que se considerou em perspectivas conteudísticas, a semântica global aposta em um "sistema que investe o discurso na multiplicidade de suas dimensões" (MAINGUENEAU, 2005, p. 80). Para isso, considera-se que não há um plano que concentraria a significação dos discursos, funcionando como um pretenso fundo, mas uma diversidade de planos que se combinariam na produção de sentido, a saber: intertextualidade, vocabulário, temas, estatuto do enunciador e do destinatário, dêixis enunciativa, modo de enunciação, modo de coesão. Reconhecendo o papel, de certo modo, organizador que os gêneros do discurso exercem em relação aos diferentes planos de instauração de sentidos, consideramos relevante também integrar parte de um debate atual a respeito da dinâmica que se estabelece entre a cena enunciativa configurada pelo gênero do discurso e aquela a que Maingueneau (2013) chamou de cenografia.

\section{Orientação discursiva: pistas de acesso às forças implicadas na enunciação}

Nossa reflexão está assim inspirada em uma perspectiva discursiva, de base enunciativa, que remonta à discussão proposta por M. Bakhtin, quando considera indissociável o vínculo entre linguagem e mundo. Para o autor,

[...] a palavra será sempre o indicador mais sensível de todas as transformações sociais, mesmo daquelas que apenas despontam, que ainda não tomaram forma, que ainda não abriram caminho para sistemas ideológicos estruturados e bem formados (BAKHTIN, 2004, p. 41).

Com efeito, percebe-se que a contribuição proporcionada por essa reflexão acerca da indissociabilidade entre o linguístico e o social permitirá rejeitar uma concepção fortemente representacional, ressaltando a impossibilidade de considerar que pudesse haver um mundo mudo em que os eventos transcorressem 
e fossem, posteriormente, "reapresentados" pela linguagem. No entanto, algo mais se diz quando argumentos contrários a uma concepção fortemente representacional ancoram os textos nas situações de interação.

Desse modo, vemos inaugurar-se aqui uma reflexão acerca da assimetria entre o linguístico e seu entorno a partir da rejeição de uma pretensa anterioridade do mundo frente à linguagem. Esse tipo de reflexão é compartilhada entre as teorias enunciativas de tradição france$\mathrm{sa}$, cujos princípios gerais poderiam ser formulados do seguinte modo: "a enunciação é considerada como um processo não intencional nem individual, e, sim, histórico e social, portanto, intimamente relacionado ao interdiscurso e aos posicionamentos discursivos" (SOUZA-E-SILVA; ROCHA, 2012, p. 31).

A partir desse quadro teórico e considerando a produtividade do tipo de perspectiva aberta pelas reflexões de M. Bakhtin, esse caminho encontrará uma sistematização importante no modo como Maingueneau definirá a prática discursiva. Propondo redimensionar o conceito originalmente formulado por M. Foucault, Maingueneau (1997) procura integrar as noções de formação discursiva e comunidade discursiva. Segundo ele, os textos não apenas pressupõem os grupos que os gerariam, mas, simultaneamente, fazem ver grupos que existiriam na e pela enunciação. Dito de outro modo, o que se afirma é
[...] a ausência de exterioridade entre coerções enunciativas e práticas institucionais, representando, desta forma, um modo de acesso privilegiado às condições de enunciação dos discursos (ROCHA, 2011, p. 11).

Assim, temos não apenas a rejeição da anterioridade da linguagem frente ao mundo, mas a abertura de uma perspectiva que consolida essa rejeição por um caminho que consideramos bastante produtivo, aquele segundo o qual a interação social modela as formas enunciativas e, simultaneamente, é legitimada pela própria enunciação.

Além de avançar na reflexão acerca da indissociabilidade entre o linguístico e o social, a perspectiva sustentada por Maingueneau ainda contribui com a possibilidade de compreender os diversos níveis em que os sentidos dos textos se produzem, observando que não há um único nível que concentrasse os sentidos de um texto, como faz sugerir a abordagem conteudista. Ao contrário, os sentidos de um texto atravessam diversos níveis, devendo serem abordados por um projeto de semântica global.

A esse respeito, destacamos o que assevera Rocha (2011) sobre a produtividade da perspectiva que sustenta a simultaneidade entre linguagem e mundo:

[...] o que se diz é efetivamente "dito" de várias maneiras: diretamente nos "conteúdos" e, não menos diretamente, no modo de dizer - uma certa escolha de tom enunciativo ou um certo exercício de língua que culmina na produção de um código linguageiro são tão constitutivos dos efeitos de sentido produzidos em um texto quanto à escolha lexical ou à seleção de um tema (ROCHA, 2011, p. 13). 
Considerando os gêneros do discurso, segundo define Maingueneau (2013), como um dispositivo comunicacional, é possível ressaltar seu papel no agenciamento dos diferentes planos da semântica global, instaurando sentido. Nessa perspectiva, recuperaremos agora 0 modo como essa noção vem sendo definida pela abordagem discursiva com a qual trabalhamos para, em seguida, tecer alguns comentários que julgamos relevantes para os debates empreendidos aqui. Essa noção é originalmente formulada por Bakhtin (2003), que parte do princípio de que os gêneros discursivos surgem da interação. Dessa forma, os diferentes tipos de textos teriam características típicas de seus usos sociais. $\mathrm{O}$ autor propõe, então, dois grandes grupos de gêneros: os primários e os secundários.

Os gêneros discursivos secundários (complexos - romances, dramas, pesquisas científicas de toda espécie, os grandes gêneros publicísticos, etc.) surgem nas condições de um convívio cultural mais complexo e relativamente muito desenvolvido e organizado (predominantemente o escrito) [...]. No processo de sua formação eles incorporam e reelaboram diversos gêneros primários (simples), que se formaram nas condições da comunicação discursiva imediata. Esses gêneros primários, que integram os complexos, aí se transformam e adquirem um caráter especial: perdem 0 vínculo imediato com a realidade concreta e os enunciados reais alheios [...] (BAKHTIN, 2003, p. 263).

O que se observa nesse tipo de reflexão é a tentativa de reafirmar uma perspectiva polifônica segundo a qual qualquer texto adquiriria sentido ape- nas quando restituído (ou recriado) ao contexto original ao qual comparece como "réplica". Daí toda a preocupação do autor em investir sobre a estabilidade, ainda que relativa, dos enunciados concretos.

A partir dessa elaboração inicial, Maingueneau (2013) sistematiza uma proposta de definição, que será aquela com a qual orientaremos nossas análises. Para o autor, uma delimitação dos gêneros do discurso deve considerar os seguintes elementos: i) uma finalidade reconhecida; ii) um estatuto legítimo entre os parceiros da troca verbal; iii) coordenadas de tempo e espaço; iv) uma organização textual; v) um suporte.

Em sua proposta, Maingueneau (2013) ressalta a diferença entre gênero e tipo de discurso: o primeiro é uma espécie de especificação do segundo. Assim, no tipo de discurso televisivo, por exemplo, existem diversos gêneros do discurso, como a novela, o talk show ou o telejornal. Da interface entre essas duas dimensões do discurso, viriam duas das três cenas consideradas pelo autor no processo de interação. $\mathrm{O}$ tipo de discurso forneceria uma cena englobante, sugerindo elementos para o adequado posicionamento do leitor, pistas mínimas para a compreensão do modo como o leitor é interpelado. Ao gênero corresponde à cena genérica, que define os papéis assumidos pelos participantes da interação e estabelece uma finalidade para a troca verbal. Dessa forma, A Escola Entre Mídias, material aqui submetido 
à análise, nos permite associar o gênero "manual" como pertencente ao tipo de discurso pedagógico.

No entanto, a própria circunscrição do material ao gênero manual não se dá sem algumas observações. Se pensarmos no sentido estrito do gênero manual, percebemos que A Escola Entre Mídias pretende ir além, já que traz informações que supostamente serviriam como aporte teórico/cultural aos docentes. Para compreender essa característica mais dinâmica do material em questão, podemos recorrer ao conceito de hipergênero que Maingueneau apresenta como

[...] um modo de organização textual com restrições fracas, que encontramos em épocas e em lugares diversos e no interior do qual encenações de fala diversificadas podem se desenvolver (MAINGUENEAU, 2004, p. 54).

Dessa forma, o gênero manual faria parte dos gêneros secundários, já que se constrói de forma mais elaborada e não advém da interação imediata, como os primários. Para analisar a relevância de um manual de uso de tecnologia para professores, o conceito de gênero parece ser bastante útil para compreender se tal material cumpre com seu papel $a$ priori. Os gêneros discursivos permitem associar determinados tipos de textos a seus usos sociais e podem ser categorizados justamente porque possuem funções minimamente definidas. A partir do momento em que a Secretaria Municipal de Educação do Rio distribui um material aos professores em que pretende orientá-los sobre o uso da tecnologia em sala de aula, parece se estabelecer um vínculo bastante próximo com o do gênero manual, em que determinado item é descrito e seu "bom funcionamento" é apresentado.

A opção inicial por tomá-lo como um manual decorre mais de uma compreensão em torno das formas de circulação, do estatuto hierárquico assimétrico entre os coenunciadores do que exatamente de uma configuração do próprio texto. $\mathrm{Na}$ delimitação aqui proposta, observamos certa gradação entre os critérios explicitados por Maingueneau (2013) acima referidos. Com isso, sustentamos que os critérios elaborados pelo autor, embora sempre presentes, se explicitam em maior ou menor grau a depender do próprio gênero e do modo como ele, em seu processo de circulação, instaura os contornos da situação de troca verbal que por meio dele se configura.

Em nossa delimitação, consideramos o fato de ter sido produzido pela MultiRio e distribuído pela Secretaria Municipal de Educação como elementos fundamentais para essa opção. Outro aspecto relevante é ter a apresentação assinada pela então Secretária de Educação do município do Rio. Esses aspectos conferem ao texto certa autoridade, que, se não apresentam coerções ao trabalho do professor, suas orientações se configuram muito ao gosto do que veio sendo produzido como documentos de orientação curricular, desde a publicação dos Parâmetros Curriculares Nacionais, em 1998. 
Dessa forma, ao resistir a uma espécie de constatação de seu pertencimento genérico, o material parece-nos bastante ilustrativo do tipo de discussão a que Rocha (2013, 2014) vem se dedicando: encenando maior ou menor grau de cristalização, todos os gêneros estão, por constituição, em condição de mobilidade, sustentando-se em um embate sempre provisório de forças. Apenas para retomar o que pretende orientar as análises aqui propostas, recuperamos o que Rocha (2013) afirma a respeito da tensão entre estabilidade relativa e mobilidade constitutiva dos gêneros do discurso. Apesar da estabilidade relativa dos gêneros, argumento que vem sendo reiterado desde M. Bakhtin (2000) como condição que viabilizaria sua existência, a mobilidade que lhes é igualmente constitutiva será afirmada como um traço sempre atualizável

[...] seja por intermédio do referido embate de forças que acaba designando o lugar ocupado pelas cenografias, seja pela constatação de que diferentes formações discursivas investirão de modos diferenciados naquilo que costumamos reconhecer como um "mesmo" gênero (ROCHA, 2013, p. 157).

Com efeito, percebe-se que o autor mobiliza de modo bastante criativo a formulação original em torno do quadro cênico. Ao evitar a anterioridade dos gêneros do discurso frente ao modo como um texto supostamente se travestiria para enunciar, essa formulação permite que se acesse um plano de criação/mutação dos gêneros que não estava de modo algum resolvida na formulação original de M. Bakhtin (2000), nem tematizada na discussão proposta por D. Maingueneau.

Para o que aqui propomos, a discussão anterior torna-se extremamente produtiva, por nos permitir analisar um material cuja definição do gênero não nos pareceu óbvia de saída. Dito de outro modo, estamos lidando com um tipo de material que não teria, no plano das formas constituídas, um pertencimento a um gênero bastante visível. Trata-se de um material que nos convoca a fazer uma opção. Ou seja, ao não se apresentar visivelmente pertencendo a um ou a outro gênero, demandou certo grau de intervenção dos pesquisadores, para iniciar a investigação proposta.

Ressaltando a produtividade da proposta originalmente formulada por D. Maingueneau (2013), Rocha (2013) anuncia seu projeto de revisão das distâncias entre a cena correspondente ao gênero do discurso - intitulada "cena genérica" - e a cenografia, ou seja, um dispositivo assentado sobre um enlaçamento paradoxal, aquele segundo o qual "a fala supõe certa situação de enunciação que, na realidade, vai sendo validada progressivamente por intermédio da própria enunciação" (MAINGUENEAU, 2013, p. 98).

Debate proposto por Rocha (2013), em vez de conceber a cenografia como um plano no qual o enunciador investiria para ocultar ou mesmo fantasiar a cena genérica, o autor prefere considerar que haveria graus variados de manifestação do investimento cenográfico, desde deslocamentos ínfimos até metamorfoses 
mais substanciais, quando já não se poderia mais ter acesso ao quadro cênico de imediato.

Tal proposta se sustenta em um rico debate que propõe extrair os gêneros do discurso de um fundo ao qual se teria mais ou menos acesso. Pretende-se, com isso, evitar a cilada de imaginar que os textos pudessem ter uma dada dimensão essencial, inescapável, à qual se poderia ter acesso por meio do desmascaramento da cenografia e pelo acesso privilegiado aos gêneros. A esse respeito, Rocha propõe que

[...] tanto o gênero quanto a cenografia são forças mais ou menos formalizadas que se confrontam na enunciação, entendida como relação entre coenunciadores num dado tempo e num dado espaço, com base em um certo suporte, etc. (ROCHA, 2013, p. 144).

Avançando na impossibilidade de supor uma estabilidade definitiva dos gêneros, uma espécie de pretensa essência genérica, o autor segue afirmando que, "enquanto totalizações, não há gêneros puros, e que toda e qualquer 'identidade' nesse sentido só pode ser um efeito do interdiscurso" (ROCHA, 2013, p. 144). A extrema diversidade dos gêneros, ressaltada em formas que oferecem certo grau de indecisão em sua definição, demonstra que as fronteiras entre eles são tênues,

[...] sendo, por isso, previsível que um dado texto se apresente em maior ou menor grau de conformidade com aquilo que consideramos como um protótipo de um certo gênero (ROCHA, 2013, p. 144-145).

Se a proposta original de Maingueneau (2013) tem a importância de destacar uma relação entre gênero e cenografia, a reformulação pretendida por Rocha (2013) tem o mérito de avançar na possibilidade de pensar a mutação dos gêneros do discurso (formas mais ou menos cristalizadas) aliada aos movimentos instituintes dos investimentos cenográficos (forças em tensão instituindo cenas). O ponto alto dessa reformulação residiria então em conceber que

[...] tal embate de forças/formas pode ter graus de visibilidade variados: pode haver uma maior ou menor exibição da presença desse elemento de alteridade que vem ressignificar as formas mais estáveis (ROCHA, 2013, p. 145).

Dessa maneira, segundo Rocha, a pretensa estabilidade dos gêneros não pode ser anterior aos jogos de forças, mas antes seria efeito desses.

Nos casos de menor visibilidade dessas forças desestabilizantes, a impressão é a de que o gênero se apresenta em estado "puro", desprovido de qualquer cenografia (ROCHA, 2013, p. 145).

No próximo item, exploraremos as pistas da semântica global no material em análise, como um investimento no debate a respeito da relação entre cena genérica e cenografia.

\section{"A Escola Entre Mídias" como interlocução entre a hierarquia e os profissionais}

Neste item, discutimos de que modo a hierarquia estabelece interlocução com os professores a esse respeito de seu 
próprio trabalho, em especial à pretensa necessidade de utilização das "novas" tecnologias. A abordagem que faremos do material distribuído pela Prefeitura do Rio aos professores da rede municipal terá como orientação um diálogo com a proposta que vem sendo sustentada por Rocha (2011, 2013, 2014), evidenciando, por um lado, a produtividade do recurso a um quadro cênico para análise dos gêneros do discurso e, por outro, a possibilidade de demonstrar os avanços explicitados na reformulação em relação à teorização inicialmente proposta a esse respeito.

Nossa proposta privilegiará uma descrição mais abrangente do material, em que já indicamos ao leitor algumas pistas que nos serviram de base para a opção de análise aqui empreendida. $\mathrm{Na}$ sequência, realizamos uma análise da introdução do material, demonstrando de que modo se pretende enquadrar essa interlocução. Em seguida, analisamos o primeiro capítulo, apontando, a partir de algumas entradas da semântica global (MAINGUENEAU, 2005), o modo como essa interlocução se realiza no material, trazendo para a cena gênero cuja definição não se poderia facilmente determinar.

\section{Uma escola "mais atrativa" e o silenciamento dos profissionais}

Desse modo, parece-nos importante iniciar a atividade crítica justamente procurando compreender não apenas o que o referido material demonstra pre- tender fazer, mas fundamentalmente percorrer os circuitos de difusão dos saberes que ele põe em cena, interrogando as premissas que ele próprio reivindica sobre aquilo que se propõe a solucionar. Em outras palavras, que contornos ele confere à situação de trabalho no cotidiano profissional na escola em relação à qual se pretende como um instrumento a ser utilizado pelos professores.

Já em sua apresentação, com autoria atribuída à então Secretaria Municipal de Educação do Rio de Janeiro, o manual sugere uma caracterização da dinâmica entre a hierarquia e os profissionais. Concebendo a tecnologia como ferramenta para a "inclusão digital" e a "ampliação do acesso dos nossos alunos ao conhecimento produzido pela humanidade", indicam-se lugares para a Secretaria e para os profissionais:

Nesse sentido, a Secretaria Municipal de
Educação tem investido em laboratórios de
informática, netbooks, banda larga, entre
outras ações que ratificam o entendimento
da parceria entre tecnologia e educação.
Porém, não podemos destituir o professor
de seu importante papel de mediador entre
a tecnologia e a aprendizagem dos alunos
(MULTIRIO, 2011, p. 7).

O trecho citado evidencia uma espécie de divisão de tarefas: à "Secretaria" cabe o investimento em infraestrutura e aos "professores", o papel de mediadores entre tecnologia e aprendizagem. Note-se ainda que esse investimento é assumido como evidência de um "entendimento" prévio, aquele que torna o vínculo entre tecnologia e educação irrefutável. Chama especial atenção o emprego da 
conjunção adversativa "porém", que não só reforça a anterioridade da hierarquia, mas também sugere sua possibilidade de neutralização das iniciativas dos profissionais, de cujo papel se poderia "destituir".

A anterioridade percebida segue sendo reafirmada no parágrafo seguinte, da Apresentação do manual:

\begin{abstract}
A Educopédia - plataforma de aulas digitais criadas pelos professores da Rede Municipal de Ensino do Rio de Janeiro - mostra-nos que a apropriação dos recursos digitais pode contribuir para aulas mais criativas, que dialoguem com a tecnologia de nosso tempo. Porém, o uso das mídias nas escolas requer um domínio e uma capacidade de identificação dos códigos inerentes a esses meios, o que pressupõe a apropriação desses códigos pelo professor. Com esse domínio, ele pode estabelecer as relações necessárias entre o currículo e a aprendizagem dos alunos, de modo a contemplar, inclusive, a leitura crítica dos meios de comunicação (MULTIRIO, 2011, p. 7).
\end{abstract}

Insiste-se aqui no encadeamento segundo o qual "a apropriação dos recursos digitais", evidenciada por mais uma iniciativa da hierarquia, é ação prévia às aulas "mais criativas". Mais uma vez, o emprego da adversativa "porém" introduz o que se supõe como cabendo ao professor: antes do "uso das mídias na escola", o professor precisaria dominar os "códigos" inerentes às mídias. Quando se reduz a necessária renovação pela qual a escola poderia passar, como uma instituição da modernidade, a uma mera tentativa de tornar a "escola mais atrativa", tal propósito assim reivindicado põe em cena uma premissa acerca das condições de realização do trabalho de formação na escola, que merece ser analisada.

Dessa forma, o que se coloca em análise aqui é o próprio imperativo segundo o qual a escola deveria se "modernizar", incorporando as "novas tecnologias", não tanto por uma dúvida quanto ao papel das ditas novas tecnologias, mas principalmente pelo modo como tal imperativo naturaliza sentidos, fixa práticas e, em grande medida, desqualifica o trabalho de formação na escola. Quando não promovemos análise adequada dos imperativos que se pretendem inquestionáveis, corremos o risco de compor com uma rede de consentimentos que têm contribuído para uma fragilização dos vínculos e uma compressão do espaço público, em favor das acelerações neoliberais.

Um exemplo disso residiria nos discursos em torno da necessidade de "tornar a escola mais atrativa". Com esse tipo de discurso sobre a escola, aponta-se um suposto problema e se associa rapidamente a uma pretensa solução: os professores deveriam ser mais criativos. Não temos dúvida de que a escola, assim como todas as demais instituições da modernidade, precisam colocar em questão seus impasses, rever seus desafios. No entanto, as soluções fáceis, como a parafernália técnica que vem sendo posta à disposição das escolas, em si mesmas podem até viabilizar iniciativas individuais, mas não parecem constituir alternativas consistentes e coletivas. Pautados pelas iniciativas de "sucesso", o que se 
perde é a produção de um coletivo de trabalho, capaz de refletir sobre impasses e propor soluções duradouras. Como agravante desse cenário, o risco que se tem com o fortalecimento dos imperativos é um consentimento com o avanço da lógica do aluno consumidor sobre a do aluno cidadão: essas práticas que situam o foco do trabalhado do professor sobre uma pretensa necessidade de motivar os alunos, captar-lhes o interesse acaba por tratá-los como "consumidores pouco satisfeitos com o produto escolar que o mercado atual lhes oferece, de modo que seria necessário cativá-los com táticas de marketing para eles voltarem a se interessar por uma mercadoria tão pouco valorizada" (SIBILA, 2012, p. 68).

Sem pretender aprofundar uma caracterização do material, apenas indicamos que a força enunciativa pretendida parece se situar no âmbito do que a perspectiva ergológica propõe ser o trabalho prescrito. Em uma perspectiva ergológica, a prescrição é compreendida como parte da atividade de trabalho, considerando-a como "um conjunto de condições e exigências a partir das quais o trabalho deverá ser realizado" (TELLES; ALVAREZ, 2004, p. 67). Isso significa dizer que o trabalho prescrito inclui tanto "as condições determinadas de uma situação de trabalho (as características do dispositivo técnico, o ambiente físico, a matéria-prima utilizada, as condições socioeconômicas etc.)", quanto "as prescrições (normas, ordens, procedimentos, resultados a serem obtidos)" (TELLES;
ALVREZ, 2004, p. 67). No manual aqui analisado, o material é produzido pela Secretaria e entra em circulação por circuitos oficiais de distribuição.

Dessa forma, ressaltamos que a cena instituída aqui é a de uma carta de apresentação, assinada pela então Secretária Municipal de Educação aos profissionais da rede. A imagem de leitor privilegiada na apresentação do material corresponde à de um professor de quem se espera apenas boa vontade para tornar a "escola mais atrativa".

\section{Quando o texto realiza o que pressupõe: profissionais silenciados e infantilizados no ambiente virtual}

Neste item, percorremos as pistas oferecidas pela proposta de semântica global, pretendendo evidenciar os deslocamentos, os movimentos operados que ora põem em cena certa configuração genérica, ora parecem querer contribuir para uma instituição de encenação distinta do que se vinha acompanhando até então. Esses movimentos se darão em um texto que faz uso recorrente de estratégias próprias do ambiente virtual, em organização hipertextual. Já na diagramação se observa a produção de uma cenografia hipertextual, visto que praticamente não se obedece à organização linear esperada em um material impresso. Privilegia-se a organização entre- 
cortada, com imagens ilustrativas do que se diz, uso de boxes com elementos que não estão diretamente conectados com o que se diz - uma espacialização mais vertical da página e uma orientação de leitura que pode percorrer a página em cortes diagonais, rompendo com a ordem linear da escrita impressa, elementos que consideramos compor um modo de enunciação do texto, já que esse tipo de organização da página impressa simula fortemente a organização hipertextual, em sua lógica de remissões a outros textos em afinidade direta ou não tanto com o que se apresenta.

Parente (1999) já indicava três vetores dessa leitura hipertextual, que ainda nos parecem importantes para a compreensão das fronteiras entre o impresso e o hipertextual:

1) a velocidade da transmissão e recuperação dos textos aumenta enormemente; 2) o leitor pode se inserir na escritura, interagir, transformar, traduzir, imprimir, enfim, ele pode mapear o texto utilizando cartas dinâmicas que lhe permitam interrogá-lo de forma jamais vista; 3 ) ele pode ainda criar textos em grupo utilizando os sistemas de groupware (PARENTE, 1999, p. 85).

A partir da descrição apresentada anteriormente, explicitaremos algumas pistas que propõem uma caracterização do modo como o próprio material produz sentidos a respeito de seu leitor ideal os professores que atuam em escolas da rede pública municipal.

Em nossas análises, foram salientes as pistas relativas à intertextualidade, por incluir elementos que evidenciam a busca por autoridade a partir da citação de outras vozes, nem sempre plenamente incorporadas ao próprio texto; à dêixis espaço-temporal, por evidenciar o modo como constroem as referências que contribuirão na produção da cenografia; ao estatuto atribuído aos parceiros da enunciação, por demonstrar um diálogo nem sempre claro com os profissionais aos quais o material se dirige.

Entre os dispositivos acionados para falar aos professores, observamos a produtividade do acesso à intertextualidade, que não se restringirá ao material verbal. Para isso, consideramos que

[...] o pertencimento a uma mesma prática discursiva de objetos de domínios intersemióticos diferentes exprime-se em termos de conformidade a um mesmo sistema de restrições semânticas (MAINGUENEAU, 2005, p. 146).

Dessa forma, o tratamento que daremos a esse tipo de citação de textos de natureza intersemiótica distinta deverá submeter-se ao conjunto do projeto em questão, evidenciando os sentidos que se tipo de citação ajuda a construir no material, em consonância com as demais estratégias.

Cabe, igualmente, considerar que "todo campo discursivo define uma certa maneira de citar os discursos anteriores do mesmo campo" (MAINGUENEAU, 2005, p. 81). Também se pode compreender que a cada discurso se impõe um modo de gerir essa relação definida no interior de um campo, visto que as restrições não seriam, a nosso ver, regularidades externas que viriam apenas impor restrição a um discurso, mas, sem 
dúvida, se afirmam ou fragilizam, explicitam ou ocultam a cada novo discurso que gere as fronteiras do próprio campo ao qual reivindica pertencimento.

Ao restringir nossas observações ao primeiro capítulo, por considerar os limites propostos pelo presente artigo, compreendemos os modos distintos de construir as citações entre o primeiro e o terceiro itens.

No primeiro item "A história da civilização escrita por meio da comunicação entre os homens", as citações de imagens parecem provocar efeitos diversos.

Ilustrações que propõem certa ambientação mais geral com a temática histórica:

- desenho estereotipado de "homens das cavernas";

- desenho estereotipado de personagens míticos (saci pererê, mula sem cabeça, curupira), entre satélites laptop e celular;

- imagem de Cristóvão Colombo;

- foto de Dorival Caymmi na Rádio Nacional.

Ilustrações que apresentam elementos explicitamente mencionados na parte verbal: imagem de pintura rupestre; escrita com hieróglifos; papiros; pergaminho; cunha utilizada em escrita cuneiforme; imagem da Prensa de Gutenberg; imagem de telégrafo sem fio.

Entre os boxes apresentados ao longo desse primeiro item, observamos três possíveis vínculos entre o que se discute e os filmes sugeridos, mesmo que não haja qualquer indicação mais explícita e o referido vínculo possa apenas ser inferido pelo leitor:

- vínculo mais direto com a temática: "A Guerra do Fogo"; "Matrix"; "A Era do Rádio";

- vínculo com o objeto em destaque: "O Nome da Rosa"; "O Show de Truman";

- vínculo com o contexto histórico: "A Conquista do Paraíso"; "2001 - Uma Odisseia no Espaço".

Nos boxes, também existem trechos de músicas que fazem referência ao meio de comunicação que está sendo apresentado, com trechos de canções como "Cantoras do rádio", de Lamartine Babo, "Flagra", de Roberto de Carvalho e Rita Lee, e "Pela internet", de Gilberto Gil. Tais músicas são apresentadas apenas para produzir certa "ambientação" com a temática. Não há qualquer desdobramento ou proposta de discussão a partir delas.

Recuperamos agora a construção de uma cronografia e uma topografia para esse primeiro item do material. A respeito da construção da dêixis, cabe preliminarmente observar que "o ato de enunciação supõe a instauração de uma 'dêixis' espaciotemporal que cada discurso constrói em função de seu próprio universo" (MAINGUENEAU, 2005, p. 93).

Desse modo, compreendemos que a cronografia construída pelo discurso terá importância na produção de uma cena na qual se procura validar o próprio ato enunciativo. No material em análise, a 
dêixis temporal se desloca das referências lineares à tensão entre continuidade e ruptura:

- tempo em sequências lineares: "Foi nesse período, que vai até 10000 a.C., que o homem começou a se expressar por meio de sons" (p. 20); "De volta ao passado" (p 20);

- tempo de continuidades: "As histórias contadas eram, como são até hoje" (p. 19); "De lá para cá, sofisticaram-se as práticas do narrar" (p. 19).

- tempo de rupturas: " $\mathrm{E}$ hoje, mais do que nunca, esse despertar do imaginário” (p. 20); “...que, nos últimos 30 anos, produziu-se um volume de informações novas maior do que nos cinco mil anos precedentes?" (p. 32); "Nesta nova era, alunos trazem para a sala de aula questionamentos, dúvidas e até mesmo certezas em razão do que aprenderam na "escola" que existe além dos muros da escola" (p. 45); "Nesse novo contexto, assume grande importância o projeto pedagógico da escola" (p. 57).

A tensão entre continuidades e rupturas a que fizemos menção anteriormente parece configurar-se de modo bastante interessante no fragmento a seguir, em que a permanência da escola é apontada como um elemento de continuidade em relação a momentos históricos anteriores. No entanto, essa aparente continuidade não se estabelece sem que haja igualmente rupturas, que parece ser o que se deseja privilegiar como concepção de tempo: "Nos dias de hoje, continua-se indo à escola, mas ela não é o único espaço reservado para a aprendizagem" (p. 40).

No que tange à dêixis espacial, notamos um fenômeno bastante instigante. Não obstante se trate de material elaborado e distribuído pela Prefeitura do Rio, não há qualquer menção particular a especificidades da cidade. A dêixis espacial constrói como referência para o que se diz uma coordenada genérica "Brasil" em oposição ao exterior, em especial Europa e Estados Unidos. Outro aspecto que merece registro é o fato de, nessa relação entre Brasil e exterior, o Brasil ser caracterizado como o espaço que recebe tecnologia vinda de fora ou ainda, quando a produz, não tem esse reconhecimento externo:

- Espaço que importa tecnologia: "A evolução da tecnologia trouxe ao Brasil" (p. 27); "A televisão chegou ao Brasil em 1950” (p. 27).

- Espaço das invenção não reconhecidas: “... que há registros de que, já em 1893, o padre e cientista brasileiro Roberto Landell teria realizado a primeira transmissão falada, sem fios, embora não tenha sido reconhecida oficialmente?" (p. 25).

Nesse primeiro item do primeiro capítulo, já vemos se delinear um modo de enunciar que parece se reiterar de diferentes formas nos demais capítulos. 
No caso específico do item em discussão, observamos um apagamento de qualquer marca mais explícita de interlocução com o leitor. Tal apagamento parece igualmente espelhar certa generalidade das informações tematizadas. No entanto, as entradas percorridas anteriormente nos autorizam a reconstituir um perfil de leitor presumido. A essa reconstituição corresponde a instauração de uma cenografia, aquela a partir da qual um enunciador se autoriza a falar ao leitor presumido.

A cenografia instituída constrói-se a partir de traços que podem ser assim sistematizados: generalização das coordenadas de espaço-tempo e das citações, obviedade das referências (os filmes sugeridos, por exemplo, são títulos reiterados nas coleções didáticas), menção enciclopédica de datas e músicas, apenas evidenciando um conhecimento igualmente genérico de referências culturais, sem vínculo explícito com o que se discute, apagamento das referências das informações apresentadas ao autor, como se correspondessem a um inventário partilhado. Desse modo, a generalização, a obviedade e o apagamento das referências parecem instituir uma cenografia estereotipada que habita uma fronteira tensa entre a enciclopédia e o próprio livro didático.

Já a imagem de leitor presumido se constrói a partir de alguns traços correspondentes a esses que contribuem para a criação da cenografia: infantilização, com imagens e referências com propósito uni- camente "lúdico"; desinformação, já que não compartilha de referências básicas; acriticidade, correspondente à aceitação de informação óbvias, que prescindem de referências. Com isso, pressupõe-se um leitor infantilizado. Além de trazer informações generalizantes e superficiais sobre a história da tecnologia, o material parece ser mais adequado a uma criança que a um profissional com ensino superior.

\section{Conclusões}

Para análise do material em questão, iniciamos pela tentativa de definição do gênero do discurso em que se inscreveria. A dificuldade inicial em propor a inscrição do material em um gênero nos pareceu elemento que mereceu atenção especial. Sem dúvida, a opção poderia ter sido a de tentar estabelecer uma dinâmica de tensão entre um pretenso "macrogênero" manual e uma diversidade de "subgêneros" que foi surgindo durante a leitura. No entanto, o que fazer com boxes, citações descontextualizadas, figuras precariamente vinculadas com o debate proposto pela coluna de opinião de um "especialista"?

Ao que parece, duas observações merecem destaque: de um lado, a extrema diversidade de gêneros, subgêneros e demais textos precariamente vinculados ao que se diz se articulam compondo uma espécie de caleidoscópio enunciativo, uma encenação de um ambiente virtual que torna a própria delimitação 
dos gêneros apresentados uma tarefa muito delicada. De outro, deve-se atentar menos para o que se diz, já que o leitor presumido parece se deslocar a todo momento de um desconhecedor do ambiente virtual, que não domina rudimentos técnicos nem certas regras de cooperação verbal, a um profissional amplamente conhecedor das técnicas de composição dos elementos mais variados (roteiros, programas de rádio, vídeos, etc.). E mais para o modo de dizer, quando os diversos recursos põem em cena o próprio mundo a respeito do qual falam:

O enunciado é, antes, a contrapartida de um dado estado de coisas que resulta dos "arranjos caleidoscópicos" de mundos que se sucedem. Ou ainda: o enunciado não diz o "mundo"; antes, pelo modo como é produzido, acopla-se ao fora, "mimetizando" esse entorno (ROCHA, 2007, p. 119).

Se não é pelas informações que traz que o manual integra o professor ao mundo das novas tecnologias, sem dúvida, algo mais ele produz, sugerindo sua defasagem em relação aos seus alunos, ressaltando um gap geracional, autorizando "especialistas" a explicar ao leitor-professor um fenômeno que estaria presente em seu próprio cotidiano profissional. Mais do que uma prática de formação, o manual parece se integrar aos rituais de um exercício do poder soberano, em que muito do ritual que se estabelece não cessa de legitimar tão somente o próprio edifício hierárquico, nada "atrativo" ao exercício profissional cotidiano do professor.
Media, daily practices and work at school: fragility of the bonds and infantile treatment of the professionals

\begin{abstract}
The aim of this paper is to discuss and discursively analyze the discussions about the work with new technologies in classroom, that has been brought to the teachers by the handbooks that aims to coach the professionals of education to be able to operate in this emerge context of interactive-media-practices in education. In order to analyze the material, specially the chosen one, that was produced by the municipal government of Rio de Janeiro in 2011, "Escola Entre Mídias", we have adopted the theoretical background inspired in a enunciative-discursive approach, that refers to the discussion proposed by M. Bakhtin (2004) concerning the dialogical perspective of language, not decoupled from the references to the world. As methodological procedure, we began by defining the speech genre, that belongs to the material under analysis. Subsequently, we conducted a mapping of discursive components, that refers to the field of global semantics (MAINGUENEAU, 2005) focused on intertextuality and temporal and spacial deixis. The results of the analysis seem to indicate to the discoursive production of an infatilized-teacher-image.
\end{abstract}

Keywords: New technologies. Education. Discourse. 


\section{Referências}

BAKHTIN, M. Estética da Criação Verbal. Tradução de Maria Ermantina Galvão. São Paulo: Martins Fontes, 2000.

. Marxismo e Filosofia da Linguagem: problemas fundamentais do método sociológico na ciência da linguagem. Trad. de Michel Lahud e Yara Frateschi Vieira. São Paulo: Hucitec, 2004.

MAINGUENEAU, D. "Diversidade dos gêneros discursivos". In: MACHADO, I. L.; MELLO, R. de (Org.). Gêneros: reflexões em Análise do Discurso. Belo Horizonte: NAD/ POSLIN/FALE-UFMG, 2004, p. 43-57.

. Gênese dos discursos. Trad. de Sírio Possenti. Curitiba: Criar, 2005.

. Análise de textos de comunicação. Trad. Cecília P. Souza-e-Silva e Décio Rocha. 6.ed. ampl. São Paulo: Cortez, 2013.

MULTIRIO. A escola entre mídias. Rio de Janeiro: MultiRio, 2011. Coleção MultiRio na Escola. Disponível em: <http://www.multirio. rj.gov.br/ebooks/escola_entre_midias/escola_ entre_midias/content/escola_entre_midias. pdf>. Acesso em: $18 \mathrm{dez} .2014$.

ROCHA, D. Acontecimento e memória (2): encontro de gêneros discursivos que (re) contam a história de um Brasil-ainda-colônia. Revista da ANPOLL (On-line), v. 37, p. 180-198, 2014. Disponível em: <http:// www.anpoll.org.br/revista/index.php/revista/ article/view/779/771>. Acesso em: $15 \mathrm{dez}$. 2014.

Cartografias em análise do discurso: rearticulando as noções de gênero e cenografia. DELTA, São Paulo, v. 29, p. 135-159, 2013.

"Enlaçamentos enunciativos em análise do discurso: quando o dizer e o dito se interlegitimam". Linguagem em (dis)curso, Tubarão, v. 11, n. 1, 2011.
Produção de subjetividade: a lição de O homem que copiava. DELTA, São Paulo, v. 23, n. 1, p. 97-126, 2007.

SIBILA, P. Redes ou paredes: a escola em tempos de dispersão. Trad. de Vera Ribeiro. Rio de Janeiro: Contraponto, 2012.

SOUZA-E-SILVA, C.; ROCHA, D. Enunciação em processo: dispositivos para a produção de uma memória discursiva. Desenredo, Passo Fundo, v. 8, n. 1, p. 30-48, 2012.

TELLES, A. L.; ALVAREZ, D. "Interfaces ergonomia-ergologia: uma discussão sobre o trabalho prescrito e normas antecedentes". In: FIGUEIREDO, M; ATHAYDE, M.; BRITO, J.; ALVAREZ, D. (Org). Labirintos do trabalho: interrogações e olhares sobre o trabalho vivo. Rio de Janeiro: DP\&A, 2004. p. 63-90. 